\title{
Microwave generation and complex microwave responsivity measurements on small Dayem bridges
}

Pedersen, Niels Falsig; Sørensen, O; Mygind, Jesper; Lindelof, Poul Erik; Levinsen, M. T.; Clark, T. D.; Danielsen, M

Published in:

I E E E Transactions on Magnetics

Link to article, DOI:

10.1109/TMAG.1977.1059394

Publication date:

1977

Document Version

Publisher's PDF, also known as Version of record

Link back to DTU Orbit

Citation (APA):

Pedersen, N. F., Sørensen, O., Mygind, J., Lindelof, P. E., Levinsen, M. T., Clark, T. D., \& Danielsen, M. (1977). Microwave generation and complex microwave responsivity measurements on small Dayem bridges. I $E E E$ Transactions on Magnetics, 13(1), 248-251. https://doi.org/10.1109/TMAG.1977.1059394

\section{General rights}

Copyright and moral rights for the publications made accessible in the public portal are retained by the authors and/or other copyright owners and it is a condition of accessing publications that users recognise and abide by the legal requirements associated with these rights.

- Users may download and print one copy of any publication from the public portal for the purpose of private study or research.

- You may not further distribute the material or use it for any profit-making activity or commercial gain

- You may freely distribute the URL identifying the publication in the public portal 
MICROWAVE GENERATION AND COMPLEX MICROWAVE RESPONSIVITY MEASUREMENTS ON SMALL DAYEM BRIDGES

$$
\begin{aligned}
& \text { N.F. Pedersen, O.H. Soerensen, J. Mygind } \\
& \text { P.E. Lindelof, M.T. Levinsen, T.D. Clark }
\end{aligned}
$$

M. Danielsen***

\begin{abstract}
Measurements of the active properties of a Dayem micro-bridge at $\mathrm{x}$-band frequencies is described. The bridge was mounted in a microwave cavity designed to match the bridge properly and the microwave output from the cavity was detected using a sensitive $\mathrm{x}$-band spectrometer. Microwave power was detected from the freely running Josephson oscillations with the bridge dc-biased to emit at the receiver frequency and the maximum power extracted was of order $10^{-12} \mathrm{~W}$ when the receiver was tuned to the cavity resonance. With an external rf-excitation of the bridge the amplitude of either the first or second harmonic response was measured. On the basis of analogue computer simulations an equivalent circuit was obtained describing the bridge coupled to the cavity. The large self inductance of the background film adjacent to the bridge was found to play a major role in explaining our results.
\end{abstract}

\section{I . INTRODUCTION}

Measurement of microwave power generation in thin film microbridges has been reported previous $1 y^{1}, 2$. In addition to the results discussed in ${ }^{2}$ this communication presents: (A) Direct detection of the amplitude of the junction voltage component at $29 \mathrm{GHz}$ (video-detection) when a small rf-current at that frequency is injected; (B) Phase sensitive detection of the junction voltage at $\sim 9 \mathrm{GHz}$ with an rf-current excitation of the junction at the same frequency; from measurement of two orthogonal components both the amplitude and phase of the junction response (impedance) may be derived, and (C) Phase sensitive detection of the second harmonic junction response (at $\approx 9 \mathrm{GHz}$ ) when the junction is excited at $24.5 \mathrm{GHz}$.

The experimental results are compared with analogue computer simulations based on the resistively shunted junction model (RSJ). The comparison reveals that the experimental results can be understood provided a selfinductance in series with the junction is added to the model, the origin of this inductance being partly the surface impedance and partly the geometry of the background film adjacent to the bridge.

Manuscript received August 17, 1976

* Physics Laboratory I, The Technical University of Denmark, DK-2800 Lyngby, Denmark

** Physics Laboratory I, H.C.ørsted Institute, University of Copenhagen, Denmark

*** Electromagnetics Institute, The Technical University of Denmark, DK-2800 Lyngby, Denmark
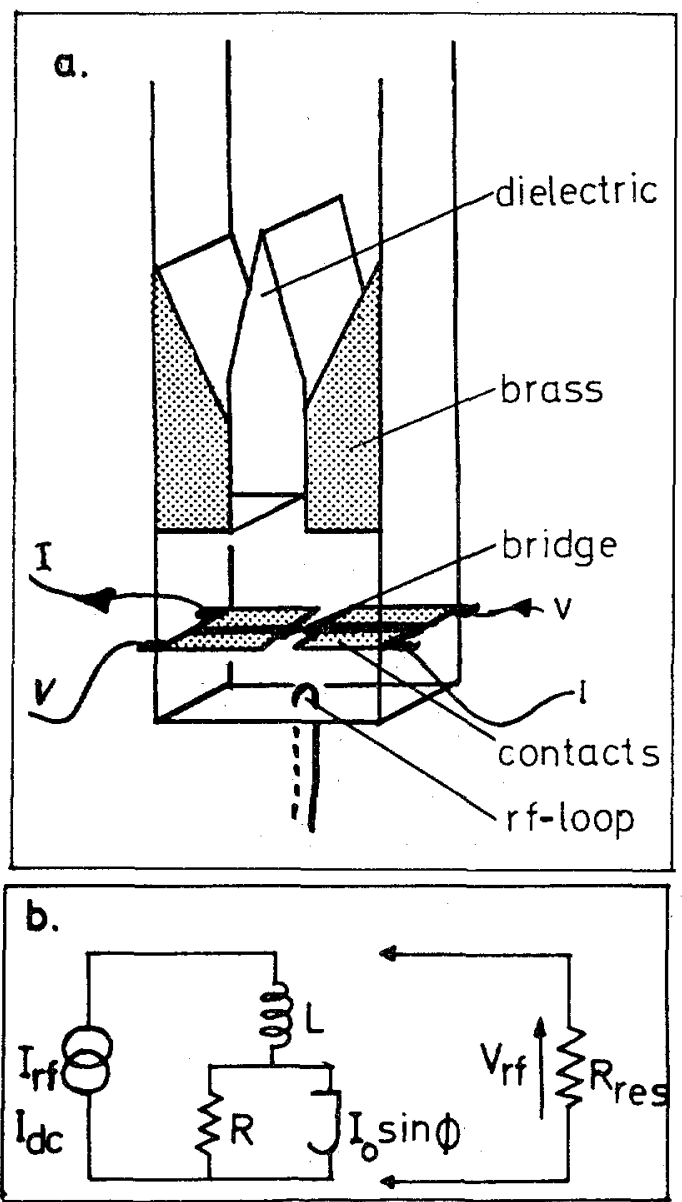

Fig. 1. a) The microwave cavity b)

Equivalent diagram at the cavity resonance.

\section{EXPERIMENTAL DETAILS}

The thin film microbridges used in these experiments were cross-scratched in 1000-2000 $\AA$ thick Indium films evaporated on $7 \times 7 \mathrm{~mm}^{2}$ glass substrates by a technique described in ${ }^{3}$. The bridges are typically less than $0.5 \mu \mathrm{m}$ long and wide.

The bridge was mounted at the end wall of an $x$-band cavity designed to provide good coupling of the Josephson oscillations into the receiver input waveguide. This is done by having the bridge being part of the end wall and using an adjustable coupling between the cavity and the waveguide as shown in Fig. la. The excitation signal at either $4-4.5 \mathrm{GHz}$ or at 8-9 $\mathrm{GHz}$ was supplied to the junction through a coaxial cable and a coupling loop mounted behind the junction. This input signal was rather badly coupled to the junction. The cavity has two resonance frequencies one at $\sim 8.5 \mathrm{GHz}$ and the other at $\sim 9.7 \mathrm{GHz}$. Both resonances had a loaded $Q$ with the junction 
mounted in position of about 500. The excitation signal was derived from a $4-4.5 \mathrm{GHz}$ transistor oscillator where either the fundamental or the second harmonic was selected by means of a tunable YIG-filer. When the receiver was operated in the phase sensitive mode the 8-9 $\mathrm{GHz}$ signal from the junction and a reference signal (the second harmonic from the transistor oscillator) were both mixed with a common local oscillator at 8-9 $\mathrm{GHz}$ using two separate $\mathrm{x}$-band mixers. The two $70 \mathrm{MHz}$ IF signals were amplified and mixed to produce a DC-signal containing information on both amplitude and phase of the junction generated response. Using a phaseshifter in the reference arm at two orthogonal settings the amplitude and phase information could be separated. The amplitude could be measured directly using the video output from the signal IF amplifier. Careful precautions were taken in order to eliminate leakage signals and a number of isolaters and a low pass filter prevented the local oscillator signal and its harmonics from reaching the function. The receiver noise figure was थ $\mathrm{dB}$.

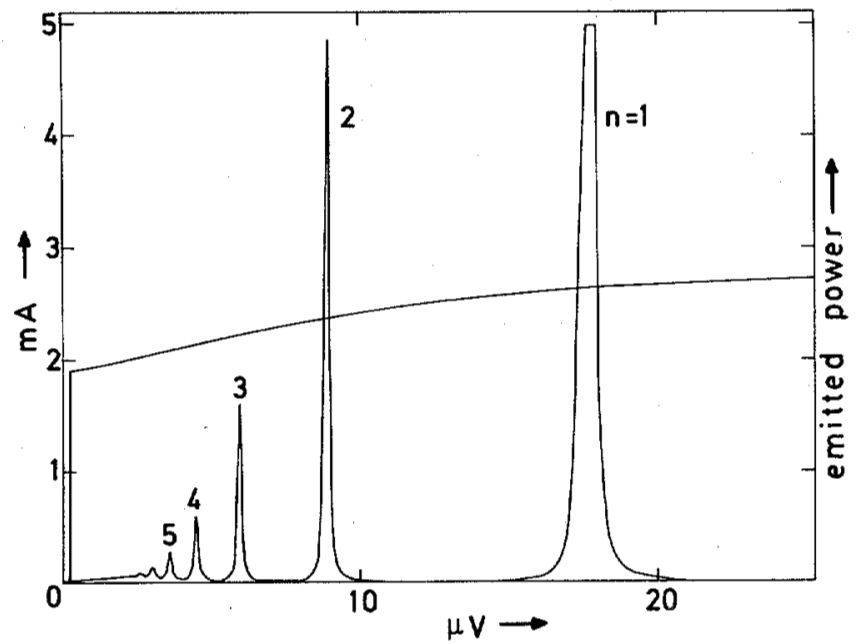

Fig.2. Emitted power at the cavity resonance frequency $\mathrm{f}_{\mathrm{LO}}=8.39 \mathrm{GHz}$.

\section{EXPERIMENTAL RESULTS}

Fig. 2 shows an example of the detected microwave power from the microbridge. In this case the receiver was tuned to detect radiation at the cavity frequency, $8.46 \mathrm{GHz}$. The fundamental peak, $n=1$, at $17.5 \mu \mathrm{V}$ is truncated due to the limited paper size. The peaks $n=2,3, \ldots, 8$, reflect that the cavity at these voltages is excited by the correspondingly numbered harmonics of the Josephson frequency. The linewidth of the radiation is typically of order $200 \mathrm{MHz}$, which with the $10 \mathrm{MHz}$ receiver pass band leads us to using the integrated power when comparing with theory. The maximum measured power, $10^{-13} \mathrm{~W}$, is low compared to the numbers quoted for point contacts ${ }^{4}$, but comparable to the recent observation of Gubankov et al. I on variable thickness bridges. Our linewidths are, however, one order of magnitude narrower than those observed on variable thickness bridges and are comparable to what has been observed on point contacts coupled directly to a waveguide ${ }^{5}$. We also measured the integral power as a function of temperature (critical current) at a frequency well off resonance. The result was that the emitted power, $\mathrm{P}_{1}$, at the fundamental $(n=1)$ follow $P_{1} \propto I^{2}$ in accordance with the resistively shunted junction model 6 if we were in the limit $\left(\mathrm{RI}_{\mathrm{C}}\right)^{2}<(\overline{\mathrm{h}} \omega / 2 \mathrm{e})^{2}$ (Using experimentally determined junction parameters we find, however, that we should not be in this limit). For the detected power at the second and third harmonics we found $\mathrm{P}_{2} \propto \mathrm{I}_{\mathrm{C}} / 3$ and $\mathrm{P}_{3} \propto \mathrm{I}_{\mathrm{G}}$ whereas the resistively shunted junction model gives $P_{n} \propto I_{C}^{2}$.
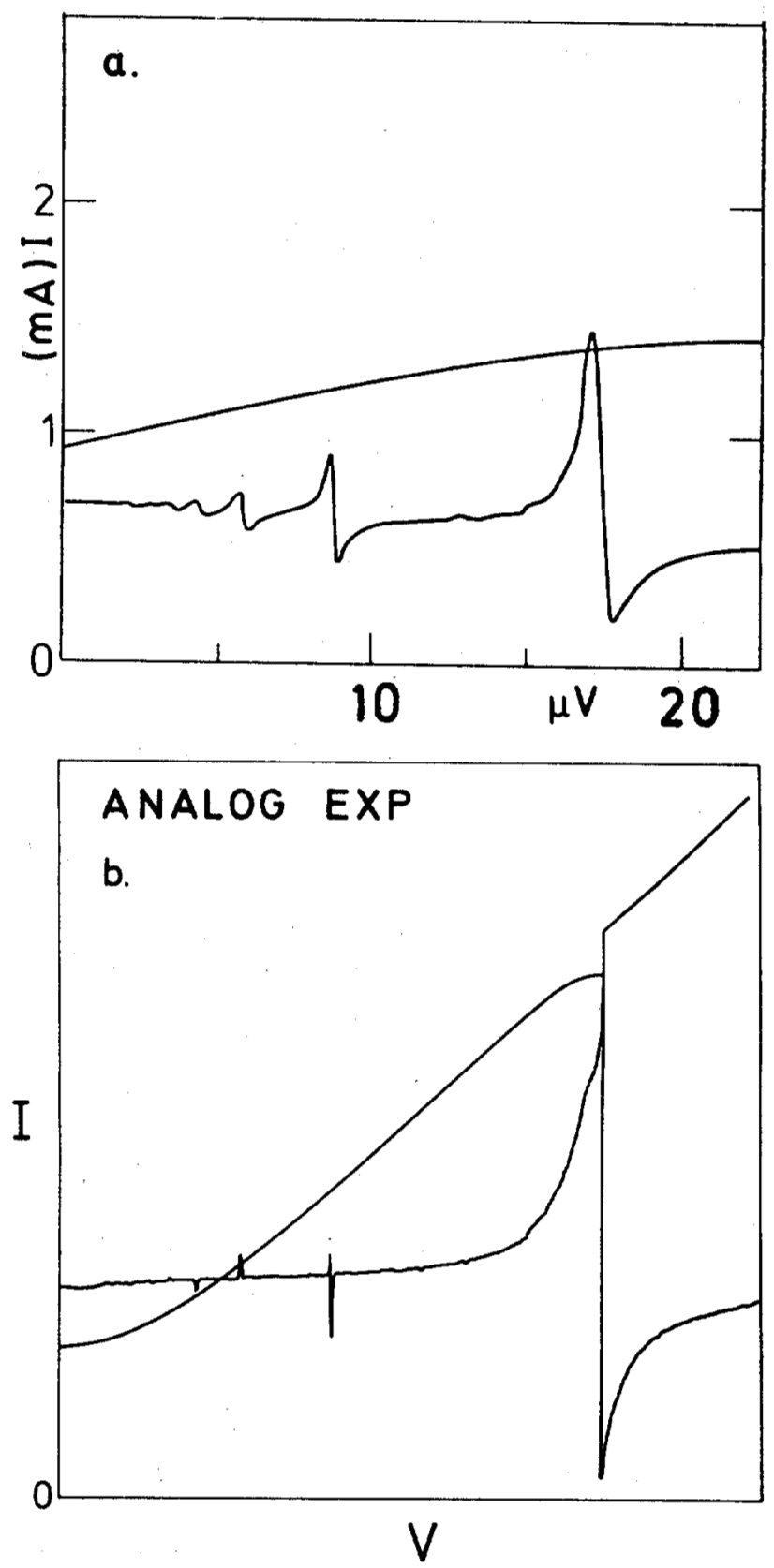

Fig.3. a) Video response to a small applied signal at the cavity resonance frequency. $\mathrm{f}_{\mathrm{I}}=8.39 \mathrm{GHz}$. b) Analog experiment corresponding to the diagram Fig. $1 \mathrm{~b}$. 
Hence, the RSJ-model cannot account in detail for the experimental results. Also in other respects discrepancies between the predictions of the simple model and experimental observations were noted. It is obvious from Fig. 2 that the IV curve of the microbridge deviates markedly from the hyperbola of the RSJ model as discussed in 7 , furthermore fractional Josephson steps appeared in the IV curve under the influence of applied radiation, and also subharmonic cavity induced structures were visible.

From measurement of the rf voltage amplitude with the junction excited by a small rf-current at the same frequency (at $8.46 \mathrm{GHz}$ for the trace shown in Fig. 3a) we conclude that in the least a self inductance in series with the junction should be added to the RSJ-model as shown in Fig. $1 \mathrm{~b}$, the argument being as follows. In Fig. 3a the applied frequency was at the cavity resonance and the excitation power level was of order or less than that of the selfgenerated Josephson oscillations. At this power level no rf-induced steps were visible in the IVcurve. Analogue computer simulation of the experimental circumstances have shown that with the series inductance included the junction response is in qualitative agreement with the experimental result as shown in Fig. 3b. By replacing the inductance by other impedances such as capacitances, resistances or combinations of these we found that the junction response as a function of bias voltage has a minimum below and a maximum above the bias voltage corresponding to the excitation frequency which is the result expected on basis of the pure RSJmodel ${ }^{7}$, and just the opposite of what was observed experimentally. OnIy with an inductance or a largely inductive impedance in series with the junction equal to or larger than the Josephson inductance, $\mathrm{I}_{\mathrm{J}}=\mathrm{h} / 2 \mathrm{eI}$, the maxima and minima appeared in the right order with a fair reproduction of the lineshape as shown in Fig. 3(a) and (b) .

Fig. 4 shows typical results obtained with the receiver operated in the phase sensitive mode. Otherwise the experimental circumstances are as discussed above. The three traces in the figure correspond to different settings of the reference phase. The phase $\theta=0$ is chosen such that the signal is zero at zero voltage and high power levels. Since the junction is rf-current driven the measured voltage components are projections of the complex junction impedance on orthogonal axes. Hence, the junction impedance may be determined apart from a complex number. In order to determine this number an assumption must be made at some bias voltage on the magnitude of the impedance. From calculations on the RSJ-model ${ }^{8}$ it is known that in the limit of large bias voltages the impedance is real and equal to the asymptotic resistance, however, the magnitude of the series inductance to be included in the model for the microbridge is not known, and we cannot make a direct comparison to the theory.

At the present stage we must merely note that also the phase sensitive measurements of the junction voltage are consistent with the presence of the series inductance.

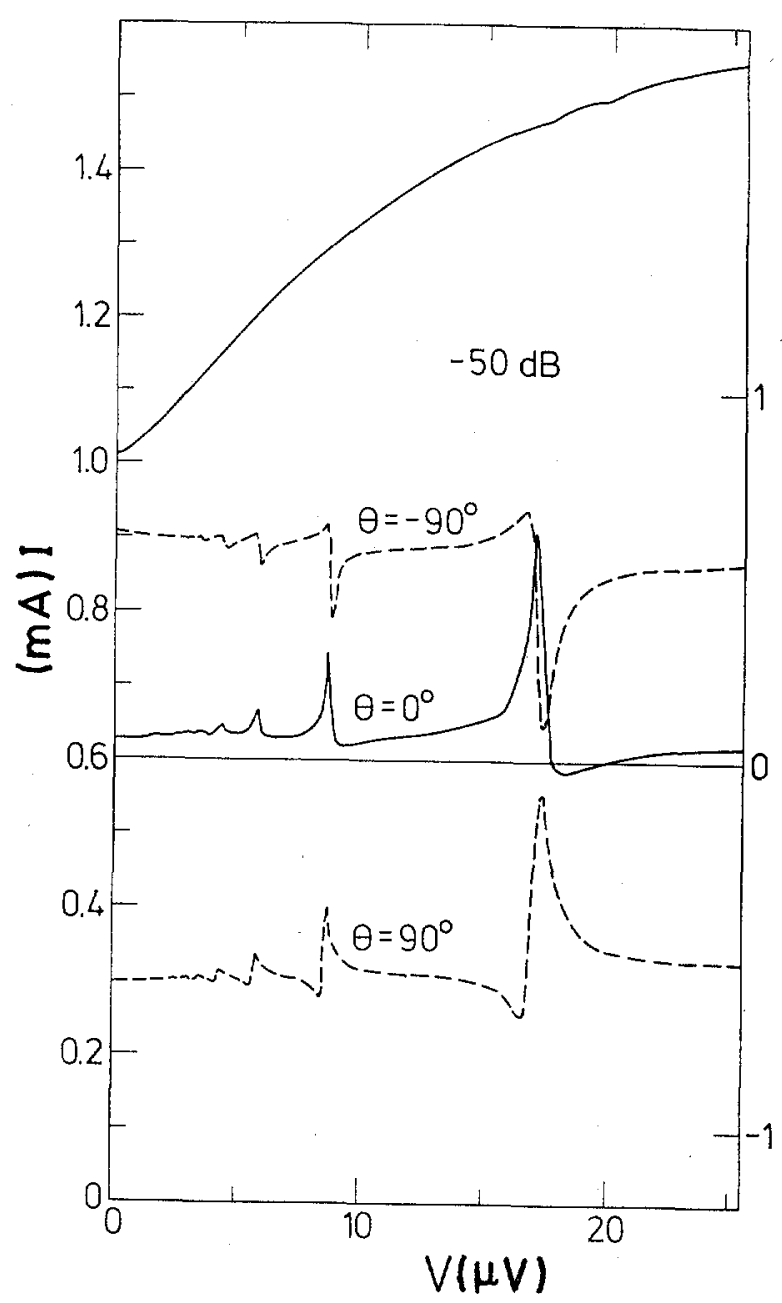

Fig. 4. Phase sensitive response to a small applied signal at the cavity resonance frequency. $\mathrm{f}_{\mathrm{IO}}=8.39 \mathrm{GHz}$.

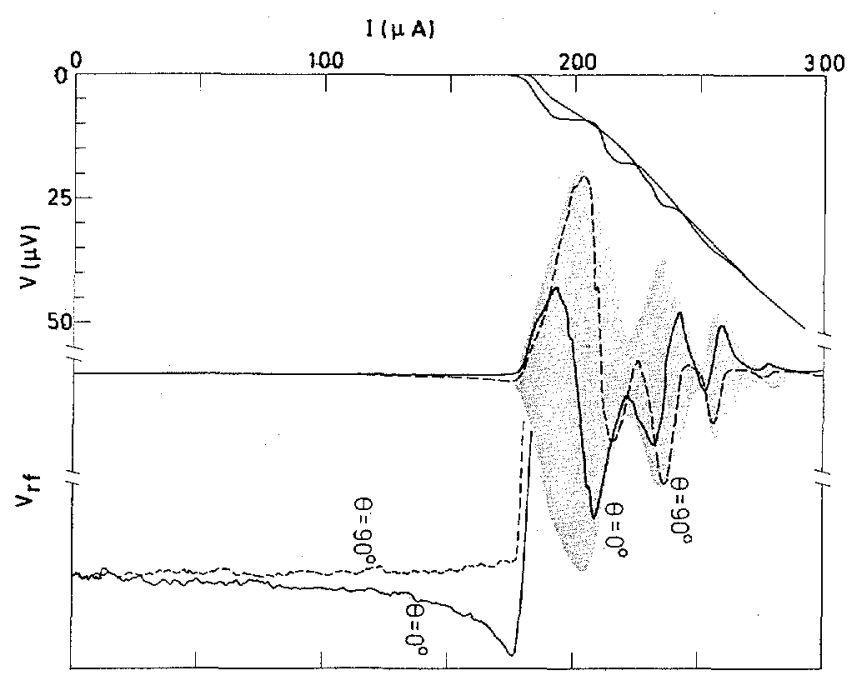

Fig. 5. Second harmonic phase sensitive response to an injected signal at $f=4.29$ $\mathrm{GHz} \cdot \mathrm{f}_{\mathrm{LO}}=8.51 \mathrm{GHz}$. 
As a first step to circumvent the voltage contribution from the (linear) series inductance we have measured the second harmonic generation from the microbridge. Typical experimental traces for a comparatively large excitation power level at 4.3 $\mathrm{GHz}$ are shown in Fig. 5. Here the second harmonic voltage is shown as a function of DC-bias current in order to show the variation along the supercurrent and on the $r f$ induced steps. The figure shows experimental traces for two orthogonal phase settings and the contour of the shaded area is the envelope of the traces for all different phase setting, i.e. the amplitude of the second harmonic signal. From this experiment the complex second harmonic conversion impedance $z_{12}=V(2 \omega) / I(\omega)$ may be determined. So far the second harmonic conversion impedance, $\mathrm{Z}_{12}$, has been evaluated theoretically only on the supercurrent ${ }^{9}$ (at zero voltage) where the second harmonic generation is due to the non-linear Josephson inductance $\mathrm{L}_{\mathrm{J}}=\mathrm{L}_{\mathrm{o}} / \cos \phi$. The weak second harmonic voltage which we have been able to resolve at zero voltage is in qualitative agreement with what should be expected from the RSJ-model. The signal is zero at zero bias current and increases as the bias current approaches the critical current reflecting the more and more pronounced non-linearity.

\section{CONCLUSION}

We have presented a direct experimental demonstration of the microwave power generation from thin film microbridges. Furthermore we have shown that detailed microwave response (complex impedance) measurements are feasible and have learned that the self inductance of the background film plays a crucial role in the interpretation of the results. This inductance and possibly also the presence of the cavity have prevented us from making a direct comparison to the simple resistively shunted junction model ${ }^{8}$. In order to take full advantage of the non-linear properties of the device the series inductance must be eliminated, e.g., by incorporating the bridge in an appropriately designed microwave stripline circuit for which this thin film structure seems very well suited.

\section{REFERENCES}

1. V.N. Gubankov, V.P. Koshelets, and G.A. Ovsyannikov, JETP Lett. 21, 226 (1975); Proc. LT 14, 4, 120 (1975)

2. N.F. Pedersen, O.H.Soerensen, and J. Mygind, P.E. Lindelof, M.T. Levinsen, and T.D. Clark, Appl.Phys.Lett. 28, 562 (1976)

3. P.E. Gregers-Hansen, M.T. Levinsen, and G. Fog Pedersen, J.Low-Temp. Phys. 7 , 99 (1972); P.E. Gregers-Hansen and $\bar{M}$.T. Levinsen, Phys.Rev.Lett. 27, 847 (1971)

4. A.H. Dayem and C.C. Grimes, Appl.Phys. Lett. $\underline{9}, 47$ (1966)

5. R. Adde and G. Vernet, J.Appl.Phys. 43, $2406(1972)$
6. A.N.Vystavkin, V.N.Gubankov, L.S.Kuzmin, K.K.Likharev, V.V.Migulin, and V.K. Semenov, Rev.Phys.Appl., Vol.9, No.1, $\underline{70}(1974)$

7. H. Hфjgaard Jensen and P.E. Lindelof, Proc. LT 14, 4, 152 (1975); J.Low-Temp. Phys. 23, $469^{-}(1976)$

8. F. Auracher and T. van Duzer, J.Appl, Phys. 44, 848 (1973)

9. A. Denenstein, Thesis, University of Pennsylvania 1968 (unpublished) N.F. Pedersen, T.F. Finnegan, D.N. Langenberg, Phys.Rev. B6, 4151 (1972) 